\title{
Chest radiography in children aged 2-59 months enrolled in the Innovative Treatments in Pneumonia (ITIP) project in Lilongwe Malawi: a secondary analysis
}

Tisungane Mvalo ${ }^{1,2^{*}}$, Eric D. McCollum ${ }^{3,4}$, Elizabeth Fitzgerald ${ }^{1,2}$, Portia Kamthunzi ${ }^{1,5}$, Robert H. Schmicker ${ }^{6}$, Susanne May ${ }^{6}$, Melda Phiri ${ }^{1}$, Claightone Chirombo ${ }^{1}$, Ajib Phiri $^{7}$ and Amy Sarah Ginsburg ${ }^{6}$

\begin{abstract}
Background: Pneumonia is the leading infectious cause of death in children aged under 5 years in low- and middleincome countries (LMICs). World Health Organization (WHO) pneumonia diagnosis guidelines rely on non-specific clinical features. We explore chest radiography (CXR) findings among select children in the Innovative Treatments in Pneumonia (ITIP) project in Malawi in relation to clinical outcomes.

Methods: When clinically indicated, CXRs were obtained from ITIP-enrolled children aged 2 to 59 months with community-acquired pneumonia hospitalized with treatment failure or relapse. ITIP1 (fast-breathing pneumonia) and ITIP2 (chest-indrawing pneumonia) trials enrolled children with non-severe pneumonia while ITIP3 enrolled children excluded from ITIP1 and ITIP2 with severe pneumonia and/or selected comorbidities. A panel of trained pediatricians classified the CXRs using the standardized WHO CXR research methodology. We analyzed the relationship between CXR classifications, enrollee characteristics, and outcomes.
\end{abstract}

Results: Between March 2016 and June 2018, of 114 CXRs obtained, 83 met analysis criteria with 62.7\% (52/83) classified as having significant pathology per WHO standardized interpretation. ITIP3 $(92.3 \%$; 12/13) children had a higher proportion of CXRs with significant pathology compared to ITIP1 $(57.1 \%, 12 / 21)$ and ITIP2 $(57.1 \%, 28 / 49)$ ( $p$-value $=0.008)$. The predominant pathological CXR reading was "other infiltrates only" in ITIP1 $(83.3 \%, 10 / 12)$ and ITIP2 (71.4\%, 20/28), while in ITIP3 it was "primary endpoint pneumonia" $(66.7 \%, 8 / 12$; $p$-value $=0.008)$. The percent of CXRs with significant pathology among children clinically cured $(60.6 \%, 40 / 66)$ vs those not clinically cured $(70.6 \%$, $12 / 17$ ) at Day 14 was not significantly different ( $p$-value $=0.58$ ).

Conclusions: In this secondary analysis we observed that ITIP3 children with severe pneumonia and/or selected comorbidities had a higher frequency of CXRs with significant pathology, although these radiographic findings had limited relationship to Day 14 outcomes. The proportion of CXRs with "primary endpoint pneumonia" was low. These findings add to existing data that additional diagnostics and prognostics are important for improving the care of children with pneumonia in LMICs.

\footnotetext{
*Correspondence: tmvalo@unclilongwe.org

1 Lilongwe Medical Relief Fund Trust, University of North Carolina Project,

Lilongwe, Malawi

Full list of author information is available at the end of the article
} original author(s) and the source, provide a link to the Creative Commons licence, and indicate if changes were made. The images or other third party material in this article are included in the article's Creative Commons licence, unless indicated otherwise in a credit line to the material. If material is not included in the article's Creative Commons licence and your intended use is not permitted by statutory regulation or exceeds the permitted use, you will need to obtain permission directly from the copyright holder. To view a copy of this licence, visit http://creativecommons.org/licenses/by/4.0/. The Creative Commons Public Domain Dedication waiver (http://creativeco mmons.org/publicdomain/zero/1.0/) applies to the data made available in this article, unless otherwise stated in a credit line to the data. 
Trial registration: ITIP1, ITIP2, and ITIP3 were registered with ClinicalTrials.gov (NCT02760420, NCT02678195, and NCT02960919, respectively).

Keywords: Chest radiography, Childhood pneumonia

\section{Introduction}

Pneumonia is the leading infectious cause of death in children under the age of 5 years in low- and middleincome countries (LMICs) [1-4]. Ongoing morbidity and mortality persist despite the introduction of conjugate vaccines for Streptococcus pneumoniae and Haemophilus influenzae type b (Hib), major bacterial causes of childhood pneumonia.

World Health Organization (WHO) Integrated Management of Childhood Illness (IMCI) guidelines used to diagnose pneumonia in resource-constrained settings rely on non-specific clinical features including cough, difficulty breathing, fast breathing-for-age and chest indrawing [5]. When imaging is clinically indicated in children with suspected pneumonia, chest radiography (CXR) has long been considered the reference standard $[6,7]$. In 2001, the WHO vaccine trials group developed a standardized research method for vaccine trials and epidemiological studies to interpret and define CXR changes in children likely attributable to bacterial pneumonia [6, 7].

CXR-confirmed pneumonia based on the WHO CXR methodology (WHO CXR-confirmed pneumonia) has been shown to correlate with laboratory features of infection or the isolation of pneumonia-causing pathogens such as $S$. pneumoniae in blood or respiratory samples [3, 8-10]. Compared to WHO IMCI-defined pneumonia, children with WHO CXR-confirmed pneumonia, are reported to have higher treatment failure rates, longer hospital stays, and higher morbidity and mortality in LMICs [9, 11-15]. Previous studies have demonstrated that no single clinical feature is adequate to predict WHO CXR-confirmed pneumonia [16-18]. However, with reports that children with pneumonia and abnormal CXRs have poorer outcomes, further data from subSaharan Africa that describes the indications for CXR imaging and the predictive value of CXR findings for pediatric outcomes appears prudent.

Patterns of WHO CXR-confirmed pneumonia may be shifting after the introduction of pneumococcal and Hib conjugate vaccines and with respiratory viruses becoming increasingly predominant $[19,20]$. Few studies to date have examined whether CXR findings are associated with outcomes of children diagnosed with pneumonia per WHO IMCI guidelines in Africa post-introduction of pneumococcal and Hib conjugate vaccines. To address these gaps, we conducted a post-hoc secondary analysis to describe the clinical indications for CXR imaging and explore CXR findings among children 2 to 59 months of age with community-acquired pneumonia in the Innovative Treatments in Pneumonia (ITIP) project at Kamuzu Central Hospital (KCH) in Lilongwe, Malawi.

\section{Methods}

\section{Setting and study population}

The pediatric ward of $\mathrm{KCH}$, a tertiary hospital in Lilongwe, has a 299-bed capacity that hospitalizes up to 25,000 children annually. The $\mathrm{KCH}$ radiology department performs approximately 9000 CXRs annually, and CXRs are requested by treating clinicians, largely for children with pneumonia either not responding to antibiotic treatment or deteriorating clinically. The $\mathrm{KCH}$ radiologist may be consulted for interpretation of CXRs when required, but CXRs are typically interpreted by the clinician providing care.

The ITIP project consisted of three studies: ITIP1, a double-blind randomized controlled clinical trial evaluating 3 days of amoxicillin dispersible tablets (DT) versus placebo DT (intervention) for non-severe fast-breathing pneumonia [21]; ITIP2, a double-blind randomized controlled clinical trial evaluating 5 versus 3 days (intervention) of amoxicillin DT for non-severe chest-indrawing pneumonia [22]; and ITIP3, a prospective observational study of clinical outcomes among children with pneumonia who were excluded from ITIP1 and ITIP2 due to severe pneumonia and/or comorbidities such as HIV exposure or infection, severe malaria, severe acute malnutrition, and/or anemia with hemoglobin $<8 \mathrm{~g} / \mathrm{Dl}$ [23]. The ITIP3 study population included children with both severe and non-severe pneumonia. Children presenting to the study sites with a history of cough and/or difficulty breathing were screened for eligibility to enroll in one of the three ITIP studies. Children enrolled in the ITIP1 or ITIP2 clinical trials were managed by ITIP study clinicians.

Those ITIP1 and ITIP2 children who demonstrated treatment failure while receiving oral study drug - amoxicillin DT or placebo DT - at Day 4 (ITIP1) or Day 6 (ITIP2) assessment or who had clinical relapse of pneumonia after Day 4 (ITIP1) or Day 6 (ITIP2) and by Day 14 follow-up visits, were hospitalized and received intravenous antibiotic treatment with benzyl penicillin and gentamicin (first-line intravenous antibiotic regimen). The pneumonia diagnosis at the time of initiating intravenous 
antibiotics was either fast-breathing pneumonia, chestindrawing pneumonia, danger sign pneumonia, or CXRconfirmed pneumonia (Table 1). In the children requiring hospitalization for pneumonia relapse, the clinical pneumonia diagnosis at the time of hospitalization could either be the same or different from the clinical diagnosis at time of enrollment. ITIP1 and ITIP2 children with treatment failure to benzyl penicillin and gentamicin were switched to ceftriaxone (second-line intravenous antibiotic regimen) by ITIP study clinicians. Children enrolled in the ITIP3 observational study were managed at the discretion of non-study $\mathrm{KCH}$ clinicians. Typically, ITIP3 children with danger sign pneumonia were hospitalized and placed on intravenous benzyl penicillin and gentamicin. Some ITIP3 children were subsequently changed to second-line intravenous antibiotic treatment with ceftriaxone due to an assessment of poor response or deterioration while on intravenous benzyl penicillin and gentamicin. ITIP3 children with HIV infection or exposure were treated as outpatients if they did not have danger signs.

\section{Data collection}

Per ITIP study standard operating procedures, anteroposterior CXRs were obtained from ITIP1 and ITIP2 children who were hospitalized and treated with second-line intravenous antibiotics due to treatment failure to first-line intravenous antibiotics, who had persistent pneumonia or relapse of pneumonia at Day 14 (study exit visit), or who had treatment failure due to isolated fever while on oral study drugs. As ITIP3 was an observational study, anteroposterior CXRs for ITIP3 children were obtained at the clinical discretion of the nonstudy $\mathrm{KCH}$ clinician. Digital CXR images were acquired from a Philips Medical Systems 989000002031 Optimus $50 \mathrm{x}$-ray machine and printed into analogue format for interpretation by CXR readers. All CXRs were independently interpreted in printed format by three interpreters masked to each other's interpretations. The three interpreters, EF, PK and TM, were trained in the WHO standardized interpretation of pediatric CXRs by a member of the WHO Chest Radiography in Epidemiological Studies working group (EDM), and all three passed standardized testing prior to performing the interpretations for this study $[6,7,24]$. TM was the third interpreter and arbitrator in cases where there were discordant CXR interpretations between the first (EF) and second (PK) interpreters.

WHO standardized interpretation of pediatric CXRs (Table 2) was undertaken to optimize comparisons with existing epidemiological and clinical studies [24]. Thus, CXR readings were divided into four categories: "primary endpoint pneumonia only"; "other infiltrates only"; "primary endpoint pneumonia and other infiltrates"; and "no significant pathology" (no pneumonia, no infiltrates or effusion) $[6,7,25]$. The first three interpretation categories were considered to be CXR interpretations with significant pathology. During data analysis, "primary end point pneumonia only" and "primary endpoint point pneumonia and other infiltrates" were combined into one category namely, "primary endpoint pneumonia".

Data were retrieved from the ITIP project databases and safety reports, and included age, sex, presence or

Table 1 Study definitions

\begin{tabular}{|c|c|}
\hline Terminology & Definition \\
\hline $\begin{array}{l}\text { World Health Organization (WHO) Integrated Man- } \\
\text { agement of Childhood IIIness (IMCI) general danger } \\
\text { signs }\end{array}$ & $\begin{array}{l}\text { Lethargy or unconsciousness, convulsions, vomiting everything, or inability to drink or breast- } \\
\text { feed }\end{array}$ \\
\hline Respiratory danger signs & $\begin{array}{l}\text { Grunting, nasal flaring, head nodding, severe chest indrawing, or hypoxemia (pulse oximetry } \\
\text { saturation<90\%) }\end{array}$ \\
\hline Fast-breathing pneumonia & $\begin{array}{l}\text { History of cough }<14 \text { days or difficult breathing with fast breathing-for-age ( } \geq 50 \text { breaths/min- } \\
\text { ute in children } 2 \text { to }<12 \text { months of age, } \geq 40 \text { breaths/minute in children } \geq 12 \text { months of age) in } \\
\text { the absence of chest indrawing and WHO IMCl general and respiratory danger signs }\end{array}$ \\
\hline Chest-indrawing pneumonia & $\begin{array}{l}\text { History of cough < } 14 \text { days or difficult breathing with chest indrawing in the absence of WHO } \\
\text { IMCI general and respiratory danger signs }\end{array}$ \\
\hline Danger sign pneumonia & $\begin{array}{l}\text { History of cough }<14 \text { days or difficult breathing and the presence of WHO IMCI general and/or } \\
\text { respiratory danger signs }\end{array}$ \\
\hline Chest radiograph (CXR)-confirmed pneumonia & $\begin{array}{l}\text { History of cough }<14 \text { days or difficulty breathing with CXR features of pneumonia per the } \\
\text { assessment of the clinician interpreting the CXR in the absence of fast breathing-for-age, chest } \\
\text { indrawing, and WHO general and respiratory danger signs }\end{array}$ \\
\hline First-line intravenous antibiotic treatment failure & $\begin{array}{l}\text { Persistence or presence of new WHO general or respiratory danger signs after at least } 2 \text { days of } \\
\text { receiving intravenous benzyl penicillin and gentamicin }\end{array}$ \\
\hline Second-line intravenous antibiotic treatment failure & $\begin{array}{l}\text { Persistence or presence of new WHO general or respiratory danger signs after at least } 5 \text { days of } \\
\text { receiving intravenous ceftriaxone }\end{array}$ \\
\hline
\end{tabular}


Table 2 World Health Organization standardized interpretation of pediatric anteroposterior chest radiographs in pneumonia epidemiological studies (adapted from Mahomed et al., 2017)

\begin{tabular}{|c|c|}
\hline Film Quality & Definition \\
\hline Uninterpretable & $\begin{array}{l}\text { Features of the image are not interpretable with respect to presence or absence of consolidation or pleural } \\
\text { effusion without additional images. }\end{array}$ \\
\hline Suboptimal & Features allow interpretation of consolidation and pleural effusion, but not of other infiltrates or findings. \\
\hline Adequate & Features allow confident interpretation of consolidation and pleural effusion as well as other infiltrates. \\
\hline \multicolumn{2}{|l|}{ Classification of findings } \\
\hline Significant pathology & Refers specifically to the presence of consolidation, infiltrates or effusion. \\
\hline Endpoint consolidation & $\begin{array}{l}\text { A dense or confluent opacity that occupies a portion or whole of a lobe or the entire lung that may or may not } \\
\text { contain air bronchogram. }\end{array}$ \\
\hline Other (non-endpoint) infiltrates & $\begin{array}{l}\text { Linear and patchy opacities (interstitial infiltrate) in a lacy pattern, featuring } \\
\text { Peribronchial thickening and multiple areas of atelectasis; it also includes minor patchy infiltrates that are not of } \\
\text { sufficient magnitude to constitute endpoint consolidation, and small areas of atelectasis that in children may } \\
\text { be difficult to distinguish from consolidation. }\end{array}$ \\
\hline Pleural effusion & $\begin{array}{l}\text { Presence of fluid in the lateral pleural space between the lung and chest wall that is spatially associated with } \\
\text { a pulmonary parenchymal infiltrate (including other infiltrate) or has obliterated enough of the hemithorax to } \\
\text { obscure any infiltrate; in most cases, this will be seen at the costo-phrenic angle or as a layer of fluid adjacent to } \\
\text { the lateral chest wall; this does not include fluid seen in the horizontal or oblique fissures. }\end{array}$ \\
\hline \multicolumn{2}{|l|}{ Conclusions } \\
\hline Primary endpoint pneumonia (PEP). & The presence of consolidation or pleural effusion, (as defined above) \\
\hline Other infiltrate & The presence of other (non-consolidation) infiltrates as defined above in the absence of a pleural effusion. \\
\hline No consolidation/infiltrate/effusion & Absence of consolidation, other infiltrates or pleural effusion. \\
\hline
\end{tabular}

absence of WHO general and/or respiratory danger signs, mid-upper arm circumference, malaria rapid diagnostic test result, HIV rapid diagnostic test result, intravenous antibiotic regimen, duration of hospital stay, and Day 14 outcome of pneumonia illness.

Conducted from March 2016 to April 2019, the three ITIP studies enrolled 5127 (ITIP1, 1126; ITIP2, 3000; ITIP3, 1001) children. However, this secondary CXR analysis included children enrolled between March 2016 and June 2018 only as this was the period when all WHO CXR methodology-trained pediatricians were available at the study site for the reading of the printed CXRs. From March 2016 and June 2018, the three ITIP studies enrolled 4274 children ies and 114 CXRs were obtained (Fig. 1). This analysis includes all CXRs

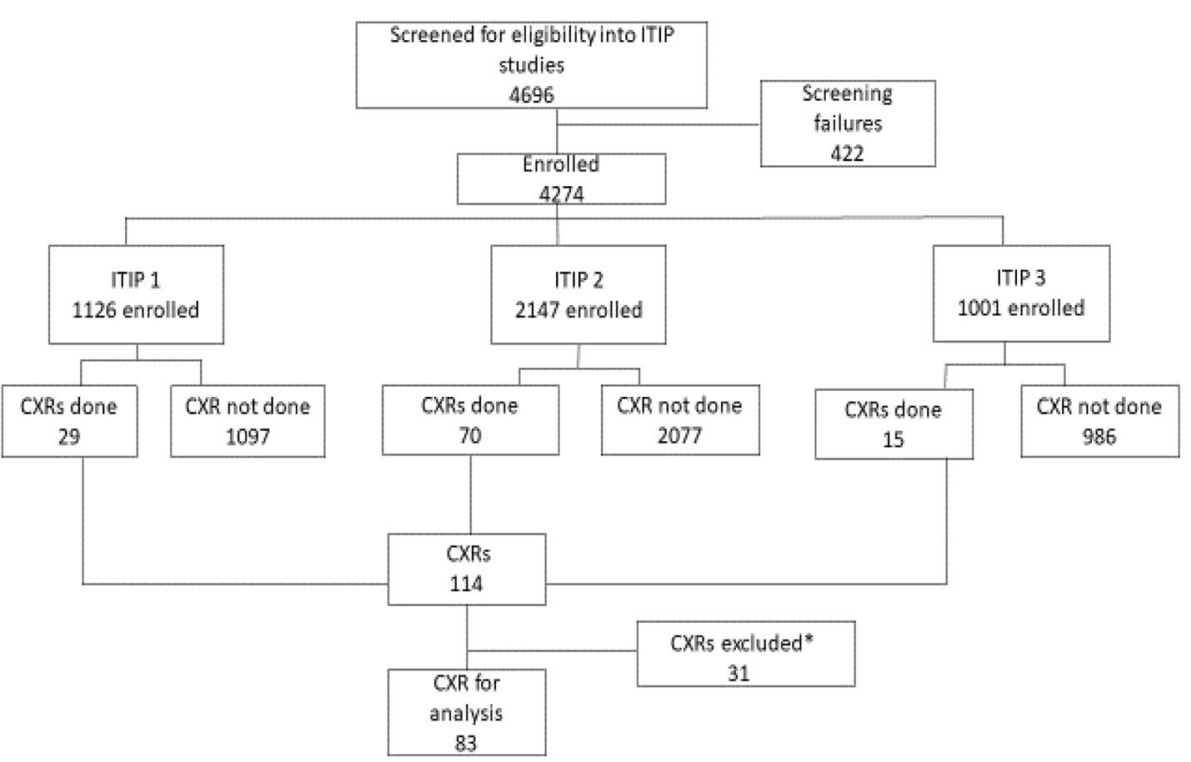

Fig. 1 Consort diagram of children who had CXR across the ITIP studies. Of the 31 CXRs excluded from this analysis, 13 were from children not hospitalized, 7 were uninterpretable CXRs, 4 had CXR reading documentation inconsistencies and 7 were duplicate CXRs 
obtained for enrolled ITIP1 and ITIP3 children, and for ITIP2 children enrolled through June 2018.

\section{Data analysis}

Clinical and safety data from the three ITIP studies were merged with the CXR findings and indications for performing CXRs. Children were excluded from this analysis if they were not hospitalized, if the CXR was uninterpretable, or if there were inconsistencies in CXR documentation. Child and CXR characteristics were stratified by ITIP study and compared by chi-squared or analysis of variance tests, depending on variable type. Pneumonia type, treatment failure, and Day 14 outcomes were stratified by CXR classification and compared by Fisher's exact tests. Concordance of CXR findings was calculated as the percentage of full matches of the CXR reading categories between the first two reviewers (EF and PK). Extracted data was tabulated on excel (Additional file 1.cxr data) and analyzed per data dictionary (Additional file 2. data dictionary). Analysis was conducted in R v3.5.1 (Vienna, Austria) [26].

\section{Results}

Of the 83 enrolled ITIP children whose CXRs were included in this analysis, $24.1 \%(21 / 83)$ were from ITIP1, $60.9 \%(49 / 83)$ were from ITIP2, and $14.9 \%(13 / 83)$ were from ITIP3 (Table 3). The majority of children in all three studies were aged 2 to 11 months. Other baseline characteristics were similar for children across the three studies with the exception of a trend for a lower mean mid-upper arm circumference in ITIP3 compared to ITIP1 and ITIP2.

CXRs demonstrating significant pathology were identified in $62.7 \%(52 / 83)$ of children across the three studies (Table 4). ITIP3 children demonstrated a higher proportion of significant pathology on CXRs (92.3\%, $12 / 13)$ in comparison to similar proportions across ITIP1 $(57.1 \%, 12 / 21)$ and ITIP2 $(57.1 \%, 28 / 49)$ children ( $p$-value $=0.008)$. Among those CXRs demonstrating significant pathology, "other infiltrates only" (65.4\%, $34 / 52$ ) was the most frequent interpretation, followed by "primary endpoint pneumonia" (34.6\%, 18/52). "Other infiltrates only" was the most frequent interpretation in $\operatorname{ITIP} 1(83.3 \%, 10 / 12)$ and ITIP2 $(71.4 \%, 20 / 28)$, while "primary endpoint pneumonia" was the most frequent interpretation in ITIP3 $(66.744 \%, 8 / 12)$. These differences noted in CXR interpretations across the three ITIP studies were statistically significant $(p$-value $=0.008)$. Of note, no CXR demonstrated a pleural effusion and $21.7 \%$ $(18 / 83)$ had a reading of "primary endpoint pneumonia."

When comparing clinical findings to CXR findings, danger sign pneumonia was present in $50 \%(9 / 18)$ of the CXR interpretations of "primary endpoint pneumonia" while danger sign and chest-indrawing pneumonias were present in $26.5 \%(9 / 34)$ of the interpretations of "other infiltrates only" (Table 5). "Primary endpoint pneumonia" was not observed in any children with fast-breathing pneumonia. Variations in CXR interpretations by WHO IMCI clinical pneumonia diagnoses or durations of hospital stay were not statistically significant.

Table 3 Baseline characteristics of children at time of enrollment into the Innovative Treatments in Pneumonia (ITIP) project at who had a chest radiograph for ITIP1 (fast-breathing pneumonia), ITIP2 (chest-indrawing pneumonia), and ITIP3 (pneumonia with comorbidities and/ or danger signs) studies

\begin{tabular}{|c|c|c|c|c|c|}
\hline Child characteristic & ITIP1 N=21 & ITIP2 N=49 & ITIP3 $N=13$ & Total $N=83$ & $p$-value \\
\hline Sex (female), n (\%) & $8(38.1)$ & $18(36.7)$ & $3(23.1)$ & $29(34.9)$ & 0.62 \\
\hline Age (months), n (\%) & & & & & 0.02 \\
\hline $2-11$ & $11(52.4)$ & $33(67.3)$ & $8(61.5)$ & $52(62.7)$ & \\
\hline $12-35$ & $7(33.3)$ & $14(28.6)$ & $5(38.5)$ & $26(31.3)$ & \\
\hline $36-59$ & $3(14.3)$ & $2(4.1)$ & $0(0)$ & $5(6.0)$ & \\
\hline Median (IQR) & $11(6,25)$ & $7(3,13)$ & $10(2,21)$ & $8(3,15.5)$ & \\
\hline Mid-upper arm circumference (mm), n (\%) & & & & & $<0.001$ \\
\hline$<115$ & $0(0.0)$ & $0(0.0)$ & $1(7.7)$ & $1(1.2)$ & \\
\hline $115-135$ & $2(9.5)$ & $17(34.7)$ & $5(38.5)$ & $24(28.9)$ & \\
\hline$>135$ & $19(90.5)$ & $32(65.3)$ & $7(53.8)$ & $58(69.9)$ & \\
\hline Positive malaria rapid diagnostic test, $\mathrm{n}(\%)$ & $1(4.8)$ & $2(4.1)$ & $3(23.1)$ & $6(7.2)$ & 0.06 \\
\hline Diarrhea present, n (\%) & $0(0.0)$ & $4(8.2)$ & $1(7.7)$ & $5(6.0)$ & 0.41 \\
\hline Fever $\left(\geq 38^{\circ} \mathrm{C}\right), \mathrm{n}(\%)$ & $7(33.3)$ & $10(20.4)$ & $3(23.1)$ & $20(24.1)$ & 0.55 \\
\hline
\end{tabular}

NOTE: $p$-values for sex, malaria, diarrhea, and fever were obtained from chi-squared tests. $p$-values for age and mid-upper arm circumference were from analysis of variance 
Table 4 Chest radiograph (CXR) findings, clinical diagnoses at time of CXR, and CXR indications for ITIP1 (fast-breathing pneumonia), ITIP2 (chest-indrawing pneumonia), and ITIP3 (pneumonia with comorbidities and/ or danger signs) studies

\begin{tabular}{|c|c|c|c|c|c|}
\hline $\mathrm{n}(\%)$ & ITIP1 $N=21$ & ITIP2 $N=49$ & ITIP3 $N=13$ & Total $N=83$ & $p$-value \\
\hline CXR findings & & & & & 0.008 \\
\hline CXR with no significant pathology & $9(42.9)$ & $21(42.9)$ & $1(7.7)$ & $31(37.3)$ & \\
\hline CXR with significant pathology & $12(57.1)$ & $28(57.1)$ & $12(92.3)$ & $52(62.7)$ & \\
\hline Primary endpoint pneumonia ${ }^{a}$ & $2(16.7)$ & $8(28.6)$ & $8(66.7)$ & $18(34.6)$ & \\
\hline Other infiltrates only & $10(83.3)$ & $20(71.4)$ & $4(33.3)$ & $34(65.4)$ & \\
\hline Pleural effusion & $0(0)$ & $0(0)$ & $0(0)$ & $0(0)$ & \\
\hline Clinical diagnoses at time of CXR & & & & & 0.006 \\
\hline Fast-breathing pneumonia & $3(14.3)$ & $7(14.3)$ & $0(0.0)$ & $10(12.0)$ & \\
\hline Chest-indrawing pneumonia & $5(23.8)$ & $22(44.9)$ & $4(30.8)$ & $31(37.4)$ & \\
\hline Danger sign pneumonia & $3(14.3)$ & $15(30.6)$ & $7(53.8)$ & $25(30.1)$ & \\
\hline Other ${ }^{b}$ & $10(47.6)$ & $5(10.2)$ & $2(15.4)$ & $17(20.5)$ & \\
\hline CXR indications & & & & & 0.001 \\
\hline $\begin{array}{l}\text { First-line intravenous antibiotic treatment } \\
\text { failure }\end{array}$ & $4(19.0)$ & $17(34.7)$ & $3(23.1)$ & $24(28.9)$ & \\
\hline Isolated fever & $9(42.9)$ & $1(2.0)$ & $1(7.7)$ & $11(13.3)$ & \\
\hline Treatment failure/relapse at Day 14 & $5(23.8)$ & $24(49.0)$ & $6(46.2)$ & $35(42.2)$ & \\
\hline Other ${ }^{c}$ & $3(14.3)$ & $7(14.3)$ & $3(23.1)$ & $13(15.7)$ & \\
\hline
\end{tabular}

$p$-values for CXR findings and CXR indications were obtained from Fisher's exact tests; $p$-value for clinical diagnoses was obtained from chi-square test

${ }^{a}$ This category consists of CXR readings of primary endpoint pneumonia with or without other infiltrates

${ }^{\mathrm{b}}$ Other clinical diagnoses included 10 CXR-confirmed pneumonia cases, 6 isolated fever cases, and 1 severe acute malnutrition case in which pulmonary tuberculosis was being investigated

' Other indications for CXR included 10 cases with an unclear or undocumented reason for ordering a CXR by requesting clinician, 1 case investigating possible foreign body aspiration, 1 case of isolated fever, and 1 case of suspected pulmonary tuberculosis

Table 5 Chest radiograph (CXR) findings in relation to clinical findings across ITIP studies

\begin{tabular}{|c|c|c|c|c|c|}
\hline \multirow[t]{2}{*}{ Clinical variable, $\mathrm{n}(\%)$} & \multicolumn{3}{|l|}{ CXR findings } & \multirow{2}{*}{$\begin{array}{l}\text { Total N (\%) } \\
\mathrm{N}=83\end{array}$} & \multirow[t]{2}{*}{$p$-value } \\
\hline & $\begin{array}{l}\text { Primary endpoint } \\
\text { pneumonia } N=18\end{array}$ & $\begin{array}{l}\text { Other infiltrates } \\
\text { only } N=34\end{array}$ & $\begin{array}{l}\text { No significant } \\
\text { pathology } N=31\end{array}$ & & \\
\hline \multicolumn{6}{|l|}{ Hospital duration ${ }^{a}$} \\
\hline $1-5$ days & $4(22.2)$ & $11(32.4)$ & $6(19.4)$ & $21(25.3)$ & 0.50 \\
\hline $6-10$ days & $9(50.0)$ & $15(44.1)$ & $16(51.6)$ & $40(48.2)$ & \\
\hline $11-15$ days & $3(16.7)$ & $7(22.6)$ & $6(19.4)$ & $16(19.3)$ & \\
\hline$\geq 16$ days & $1(5.6)$ & $0(0)$ & $3(9.7)$ & $4(4.8)$ & \\
\hline \multicolumn{6}{|l|}{ Clinical pneumonia diagnosis $^{b}$} \\
\hline Fast-breathing pneumonia & $0(0)$ & $5(14.7)$ & $5(16.3)$ & $10(12.0)$ & 0.08 \\
\hline Chest-indrawing pneumonia & $5(27.8)$ & $9(26.5)$ & $17(54.8)$ & $31(37.3)$ & \\
\hline Danger sign pneumonia ${ }^{c}$ & $9(50.0)$ & $9(26.5)$ & $7(22.6)$ & $25(30.1)$ & \\
\hline Treatment failure on intravenous antibiotics & & & & & 0.09 \\
\hline Treatment failure on first-line intravenous antibiotics & $9(50.0)$ & $9(26.5)$ & $12(38.7)$ & $30(36.1)$ & \\
\hline Treatment failure on second-line intravenous antibiotics & $5(27.8)$ & $0(0)$ & $1(3.2)$ & $6(7.2)$ & \\
\hline \multicolumn{6}{|l|}{ Day 14 assessment } \\
\hline Cured at time of Day 14 visit & $11(61.1)$ & $29(85.3)$ & $26(83.9)$ & $66(79.5)$ & 0.11 \\
\hline Not cured at time of Day 14 visit & $7(38.9)$ & $5(14.7)$ & $5(16.1)$ & $17(20.5)$ & \\
\hline
\end{tabular}

$p$-value for hospital duration was obtained via analysis of variance. Hospital duration variables were missing for 2 children. Values for pneumonia diagnosis, treatment failure on intravenous antibiotics, and Day 14 assessment were obtained from a Fisher's exact test

${ }^{\text {a }}$ Hospital duration variables were missing for 2 children

${ }^{\mathrm{b}}$ The total from the WHO pneumonia diagnosis equals 66; 17 children who had a CXR did not fall into this clinical diagnosis (10 had CXR-confirmed pneumonia, 6 had isolated fever, and 1 had severe acute malnutrition)

${ }^{c}$ Among children with danger sign pneumonia, 17 had severe chest indrawing, 11 nasal flaring, 5 head nodding, 2 grunting, and 2 hypoxemia 
Treatment failure after first-line intravenous antibiotics was observed in $36.1 \%$ (30/83) of the ITIP children who had an interpretable CXR, 60\% (18/30) of whom had a CXR demonstrating significant pathology. "Primary endpoint pneumonia" on CXR was noted in 30\% (9/30) and "other infiltrates only" on CXR was present in 30\% (9/30) of cases of treatment failure to first-line intravenous antibiotics. Treatment failure after second-line intravenous antibiotics occurred in 6 children. Among these children, $83 \%(5 / 6)$ had a CXR demonstrating significant pathology. "Primary endpoint pneumonia" was the CXR interpretation in all 5 of these children The proportion of CXRs demonstrating significant pathology among patients clinically cured at Day 14, compared to patients not clinically cured, was not significantly different $(60.6 \%$ $(40 / 66)$ vs $70.6 \%(12 / 17) ; p$-value $=0.58)$. One ITIP3 child in this analysis died and the CXR showed "primary endpoint pneumonia."

\section{Discussion}

We found important variation in CXR interpretations among children enrolled in the three ITIP studies that was largely consistent with the child's risk profile. CXRs demonstrating "primary endpoint pneumonia" or "other infiltrates only" were observed more frequently in the higher-risk ITIP3 children with severe pneumonia and/or comorbidities. On the other hand, children in ITIP1 and ITIP2 were by trial design low-risk, and we found their CXRs demonstrated either "no significant pathology" or "other infiltrates only" more frequently. CXRs with "primary endpoint pneumonia" were noted in $22 \%$ of all ITIP CXRs analyzed. Overall, the CXR patterns we observed may suggest that in the post-pneumococcal and Hib conjugate vaccine era, low-risk African children with WHO IMCI non-severe pneumonia who are failing antibiotic treatment are likely to have either nonbacterial lower respiratory infections or non-pulmonary illnesses altogether, while higher-risk children with severe pneumonia and/or comorbidities who are also failing antibiotics may have bacterial lower respiratory infections less responsive to primary antibiotic therapies.

CXR findings may help identify children with a higher or lower probability of bacterial or viral lower respiratory infection etiology. More specifically, CXRs with "other infiltrates only" may have a higher probability of viral etiology and CXRs with "primary endpoint pneumonia" may have a higher probability of bacterial etiology, while a combination of the two may suggest both viruses and bacteria as causative pathogens $[3,7,8,11]$. The PERCH studies in children hospitalized with severe pneumonia in Africa and Asia reported 61.4\% as having viral etiology [27]. Studies in South Africa reported the isolation of at least one virus in $87 \%$ of pneumonia cases
[28]. Other studies have shown associations between higher-risk, severe cases of pneumonia with polymicrobial infection [19]. In our ITIP studies, the predominance of "other infiltrates only" (65\%) on CXR implies viruses may be important pathogens in pneumonia cases in Malawi post-pneumococcal and Hib conjugate vaccine introduction. While we identified "other infiltrates only" frequently in our analysis, a study in India prior to the introduction of pneumococcal conjugate vaccine found "primary endpoint pneumonia" readings to be more frequent among CXRs from children with pneumonia [29]. In this analysis, we did not observe any statistically significant relationship between CXR findings and Day 14 clinical outcomes. However, point estimates suggest a higher proportion of children with 'primary endpoint pneumonia' may have remained ill on Day 14 than those without 'primary endpoint pneumonia.' Apart from antibiotic susceptibility of the pneumonia-causing pathogen, patient factors such as comorbidities, severity of illness on presentation, and inflammatory responses may affect the speed of recovery [30]. It is possible these may be effect modifiers on the relationship between CXR findings and outcomes. Given the relatively small sample size of this study, a larger study is needed to further explore this possibility.

Similar to other studies in LMICs that used standardized WHO research methodology to interpret CXRs, our analysis revealed nearly $40 \%$ of ITIP children with CXRs and first-line intravenous antibiotic failure were without significant CXR pathology. Furthermore, most children lacking CXR pathology were low-risk since they were classified as non-severe and lacked comorbidities [17, 31, 32]. It is notable that having a CXR without significant pathology does not exclude pneumonia in a child with respiratory signs. CXRs frequently miss alveolar consolidation identifiable on chest-computed tomography or the development of radiological abnormalities may lag the clinical presentation [18, 33, 34]. While chest computed tomography demonstrates high sensitivity and specificity for parenchymal lung disease, its routine use is infeasible in children, especially those in resource-constrained LMICs, given high ionizing radiation exposure and costs $[35,36]$. Biomarkers like procalcitonin may offer an alternative to increase sensitivity for bacterial pneumonia or predicting those at risk of adverse outcomes [37, 38].

Among higher-risk children failing antibiotics, CXRs may be clinically indicated in part to exclude complications like pleural effusions [39]. It may be that we failed to identify any pleural effusions in the ITIP studies due to the limited number of CXRs collected or that pleural effusions were too small to visualize. All CXRs obtained in ITIP were supine anteroposterior images as this is the standard approach for imaging children at $\mathrm{KCH}$. Supine 
CXR images can limit the detection of small pleural effusions, and while erect posterioanterior CXR images are preferred, they are not commonly obtained in young children due to challenges with compliance [40]. In addition, the absence of pleural effusions on CXR in our study may also be due to the changing epidemiology of pneumonia post-pneumococcal and Hib conjugate vaccine introduction [10]. A South African study evaluating children suspected of having pulmonary tuberculosis reported a higher proportion of pleural effusions using lung ultrasound (LUS) than CXR (15\% versus 9\%) [41]. Another study in Italy identified 28 more small-volume pleural effusions with LUS compared to CXR, among 47 children with pneumonia [42]. Our findings suggest clinicians may consider utilizing other imaging modalities like LUS rather than CXR to exclude pleural effusions.

Among children with suspected pneumonia confirmed by chest computed tomography, LUS has demonstrated a sensitivity and accuracy of 0.906 and 0.661 , respectively in comparison to CXR which had a sensitivity and accuracy of 0.79 and 0.559 , respectively [35]. Furthermore, LUS expert interpreters have achieved substantially higher interrater reliability compared to CXR expert interpreters [43]. Without ionizing radiation as a limitation, LUS may be useful to monitor treatment changes and possibly differentiate features of viral versus bacterial pneumonia [44-46]. LUS may also identify features of acute respiratory distress syndrome or lung changes noted in malaria and sepsis [47]. Early identification of children with acute respiratory distress or changes from malaria may improve their outcomes if appropriately triaged and managed. However, both CXR and LUS have their limitations. Aside from the difficulty in routinely capturing high-quality images in many resource-constrained settings, CXRs may have interpretation inaccuracies due to the reading of overlapping intrathoracic tissue and LUS may have challenges in identifying more centrally located lesions and lung abscesses [35, 48].

This study has several limitations. Our small sample size of hospitalized children receiving CXR examinations limits the generalizability of our results. In the ITIP studies, CXRs were ordered when clinically indicated rather than as a routine research procedure, which is reflective of actual pediatric clinical practice in LMICs. Given the current paucity of similar contemporary studies from LMICs, we believe the analysis of this relatively small sample adds hypothesis generating value in light of its rigor and real-world application. Another limitation to this project was the use of the WHO methodology for CXR interpretation. Although the WHO methodology is often applied to epidemiologic studies, the approach was originally designed to prioritize specificity and reproducibility for identifying children likely to have bacterial pneumonia participating in vaccine efficacy and effectiveness studies. For example, this approach does not take into account mediastinal or hilar lymphadenopathy that may suggest pulmonary tuberculosis, or other important findings like cardiomegaly or pneumothorax. This methodological gap limits our ability to comment on other findings that may explain the lack of improvement in children imaged with CXRs in ITIP. In the post-pneumococcal and Hib conjugate vaccine era, this suggests WHO-defined abnormal CXRs are more frequently associated with antibiotic failure [49].

\section{Conclusions}

The lower frequency of CXRs with significant pathology among low-risk children failing oral antibiotic treatment suggests clinicians should consider more aggressive pursuit of alternative non-pneumonia diagnoses when antibiotic failure occurs. In our study, among higher-risk children, CXRs consistent with a bacterial lower respiratory infection did not predict Day 14 outcomes. The proportion of CXRs with primary endpoint pneumonia among children with a clinical diagnosis of pneumonia was low. The development and validation of alternative diagnostics, prognostics, and/or ancillary tests that can augment the yield and/or replace CXRs will be important for improving the care and outcomes of children with pneumonia in LMICs.

\section{Abbreviations}

CXR: Chest radiography; DT: Dispersible tablets; Hib: Haemophilus influenzae type b; IMCI: Integrated Management of Childhood IIIness; ITIP: Innovative Treatments in Pneumonia; KCH: Kamuzu Central Hospital; LMIC: Low- and middle-income countries; LUS: Lung ultrasound; WHO: World Health Organization..

\section{Supplementary Information}

The online version contains supplementary material available at https://doi. org/10.1186/s12887-021-03091-3.

Additional file 1. cxr data.

Additional file 2. Data dictionary.

\section{Acknowledgements}

We would like to acknowledge caregivers and children for their consent and participation in these trials. We would also like to acknowledge the UNC

Project Malawi ITIP study team members and the staff of the KCH Department of Paediatrics and Child Health for their collaborative efforts in conducting the ITIP studies.

\section{Authors' contributions}

TM provided project administration and oversaw study implementation locally, contributing to the study methodology, overseeing data collection and curation, and performing CXR interpretations. TM also wrote the first draft of the manuscript. EDM contributed to the study methodology, trained and accredited the CXR interpreters, provided guidance for the CXR analysis plan, and helped write the manuscript. EF and PK performed CXR interpretations. MP and CC collected and curated the data. RHS performed the data analysis. ASG obtained the funding, conceptualized and designed the project, oversaw 
project administration, supervised the overall project and data curation, provided guidance for the CXR analysis plan, and helped write the manuscript. All authors critically reviewed and approved the submitted final manuscript.

\section{Funding}

This work was supported by a grant from the Bill and Melinda Gates Foundation [OPP1 105080]. The Bill and Melinda Gates Foundation had no role in either the design of the study, data collection and analysis, interpretation of data or writing of this manuscript.

\section{Availability of data and materials}

All data generated or analysed for this analysis are included in this published article and supplementary information files.

\section{Declarations}

\section{Ethics approval and consent to participate}

The ITIP project was conducted under the International Conference on Harmonization Good Clinical Practice guidelines and the principles of the Declaration of Helsinki. Ethical approvals were received from the Western Institutional Review Board in the USA and the Malawi College of Medicine Research Ethics Committee prior to commencement of study procedures. The ITIP1 and ITIP2 clinical trials also received regulatory approval from the Malawi Pharmacy Medicines and Poisons Board. Written informed consent from parents or caregivers was obtained prior to any study procedures. ITIP1, ITIP2, and ITIP3 were registered with ClinicalTrials.gov (NCT02760420, NCT02678195, and NCT02960919, respectively).

\section{Consent for publication}

Not applicable.

\section{Competing interests}

The authors declare that they have no competing interests.

\section{Author details}

${ }^{1}$ Lilongwe Medical Relief Fund Trust, University of North Carolina Project, Lilongwe, Malawi. ' Department of Pediatrics, School of Medicine, University of North Carolina at Chapel Hill, Chapel Hill, North Carolina, USA. ${ }^{3}$ Global Program in Respiratory Sciences, Eudowood Division of Pediatric Respiratory Sciences, Department of Pediatrics, School of Medicine, Johns Hopkins University, Baltimore, MD, USA. ${ }^{4}$ Department of International Health, Bloomberg School of Public Health, Johns Hopkins University, Baltimore, MD, USA. ${ }^{5}$ Institute for Global Health and Infectious Diseases, University of North Carolina at Chapel Hill, Chapel Hill, North Carolina, USA. ${ }^{6}$ University of Washington Clinical Trial Center, Seattle, Washington, USA. ${ }^{7}$ Department of Pediatrics and Child Health, College of Medicine, University of Malawi, Lilongwe Campus, Lilongwe, Malawi.

Received: 19 May 2021 Accepted: 20 December 2021

Published online: 10 January 2022

\section{References}

1. Komurian-Pradel F, Endtz H, Rakoto-Andrianarivelo M, Bavdekar A, Russomando G, Sylla M, et al. Severity of pneumonia in under 5-year-old children from developing countries: a multicenter, prospective, observational study. Am J Trop Med Hyg. 2017;97(1):68-76 Available from: http:// www.ajtmh.org/content/journals/10.4269/ajtmh.16-0733.

2. Hazir T, Bin NY, Abbasi S, Ashraf YP, Khurshid J, Tariq P, et al. Comparison of oral amoxicillin with placebo for the treatment of World Health Organization-defined nonsevere pneumonia in children aged 2-59 months: a multicenter, double-blind, randomized, placebo-controlled trial in Pakistan. Clin Infect Dis. 2011;52(3):293-300.

3. Enwere G, Cheung YB, Zaman SMA, Akano A, Oluwalana C, Brown O, et al. Epidemiology and clinical features of pneumonia according to radiographic findings in Gambian children. Tropical Med Int Health. 2007;12(11):1377-85.

4. Wardlaw T, Salama P, Johansson EW, Mason E. Pneumonia: the leading killer of children. Lancet. 2006;368(9541):1048-50.
5. World Heath Organization. Integrated Management of Chilhood Illness. Chart Booklet 2014

6. World Health Organization pneumonia vaccine trial investigator' group. Standardization of interpretation of chest radiographs for the diagnosis of pneumonia in children; 2001. p. 1-39. Available from: whqlibdoc.who. int/hq/2001/WHO_V\&B_01.35.pdf

7. Cherian T, Mulholland EK, Carlin JB, Ostensen H, Amin R, De Campo M, et al. Standardized interpretation of paediatric chest radiographs for the diagnosis of pneumonia in epidemiological studies. Bull World Health Organ. 2005;83(5):353-9.

8. Falup-Pecurariu OG, Diez-Domingo J, Esposito S, Finn A, Rodrigues F, Spoulou V, et al. Clinical and laboratory features of children with community-acquired pneumonia are associated with distinct radiographic presentations. Eur J Pediatr. 2018;177(7):1111-20.

9. Patel A, Mamtani M, Hibberd PL, Tuan TA, Jeena P, Chisaka N, et al. Value of chest radiography in predicting treatment response in children aged 3-59 months with severe pneumonia. Int J Tuberc Lung Dis. 2008;12(11):1320-6.

10. Ferrero F, Nascimento-Carvalho CM, Cardoso MR, Camargos P, March MFP, Berezin E, et al. Radiographic findings among children hospitalized with severe community-acquired pneumonia. Pediatr Pulmonol. 2010;45(10):1009-13.

11. Magree HC, Russell FM, Sa'aga R, Greenwood P, Tikoduadua L, Pryor J, et al. Chest X-ray-confirmed pneumonia in children in Fiji. Bull World Health Organ. 2005;83(6):427-33.

12. Kelly MS, Crotty EJ, Rattan MS, Wirth KE, Steenhoff AP, Cunningham CK, et al. Chest radiographic findings and outcomes of pneumonia among children in Botswana. Pediatr Infect Dis J. 2016;35(3):257-62.

13. Dembele BPP, Kamigaki T, Dapat C, Tamaki R, Saito M, Saito M, et al. Aetiology and risks factors associated with the fatal outcomes of childhood pneumonia among hospitalised children in the Philippines from 2008 to 2016: a case series study. BMJ Open. 2019;9(3).

14. Williams DJ, Zhu Y, Grijalva CG, SelfWH, Harrell FE, Reed C, et al. Predicting severe pneumonia outcomes in children. Pediatrics. 2016;138(4).

15. Pervaiz F, Chavez MA, Ellington LE, Grigsby M, Gilman RH, Miele CH, et al. Building a prediction model for Radiographically confirmed pneumonia in Peruvian children: from symptoms to imaging. Chest. 2018;154(6):1385-94. https://doi.org/10.1016/j.chest.2018.09.006.

16. Rambaud-Althaus C, Althaus F, Genton B, D'Acremont V. Clinical features for diagnosis of pneumonia in children younger than 5 years: a systematic review and meta-analysis. Lancet Infect Dis. 2015;15(4):439-50.

17. Fancourt N, Knoll MD, Baggett HC, Brooks WA, Feikin DR, Hammitt LL, et al. Chest radiograph findings in childhood pneumonia cases from the multisite PERCH study. Clin Infect Dis. 2017;64(August):S262-70.

18. Rees CA, Basnet S, Gentile A, Gessner BD, Grady AFO, Kartasasmita CB, et al. An analysis of clinical predictive values for radiographic pneumonia in children; 2020. p. 1-11.

19. le Roux DM, Zar HJ. Community-acquired pneumonia in children - a changing spectrum of disease. Pediatr Radiol. 2017;47(11):1392-8.

20. Theodoratou E, Johnson S, Jhass A, Madhi SA, Clark A, Boschi-Pinto C, et al. The effect of Haemophilus influenzae type $b$ and pneumococcal conjugate vaccines on childhood pneumonia incidence, severe morbidity and mortality. Int J Epidemiol. 2010;39(SUPPL. 1):i172-85.

21. Ginsburg AS, Mvalo T, Nkwopara E, McCollum ED, Ndamala CB, Schmicker $\mathrm{R}$, et al. Placebo vs Amoxicillin for Nonsevere Fast-Breathing Pneumonia in Malawian Children Aged 2 to 59 Months, A Double-blind, Randomized Clinical Noninferiority Trial. JAMA Pediatr. https://doi.org/10.1001/jamap ediatrics. 2018.3407.

22. Ginsburg AS, May SJ, Nkwopara E, Ambler G, McCollum ED, Mvalo T, et al. Methods for conducting a double-blind randomized controlled clinical trial of three days versus five days of amoxicillin dispersible tablets for chest indrawing childhood pneumonia among children two to 59 months of age in Lilongwe, Malawi: a study protoc. BMC Infect Dis. 2018;18(1). https://doi.org/10.1186/s12879-018-3379-z.

23. Ginsburg AS, May S, Nkwopara E, Ambler G, McCollum ED, Mvalo T, et al. Clinical Outcomes of Pneumonia and Other Comorbidities in Children Aged 2-59 Months in Lilongwe, Malawi: Protocol for the Prospective Observational Study "Innovative Treatments in Pneumonia". JMIR Res Protoc. 2019;8(8):e16007. https://doi.org/10.2196/16007.

24. Mahomed N, Fancourt N, de Campo J, de Campo M, Akano A, Cherian $\mathrm{T}$, et al. Preliminary report from the World Health Organisation 
chest radiography in epidemiological studies project. Pediatr Radiol. 2017:47(11):1399-404.

25. Elemraid MA, Muller M, Spencer DA, Rushton SP, Gorton R, Thomas MF, et al. Accuracy of the interpretation of chest radiographs for the diagnosis of paediatric pneumonia. PLoS One. 2014;9(8):4-9.

26. Development R. Core team: $\mathrm{R}$ : a language and environment for statistical computing. Vienna: R Foundation for Statistical Computing; 2013.

27. O'Brien KL, Baggett HC, Brooks WA, Feikin DR, Hammitt LL, Higdon MM, et al. Causes of severe pneumonia requiring hospital admission in children without HIV infection from Africa and Asia: the PERCH multi-country case-control study. Lancet. 2019;6736(19):1-23.

28. Zar HJ, Barnett W, Stadler A, Gardner-Lubbe S, Myer L, Nicol MP. Aetiology of childhood pneumonia in a well vaccinated south African birth cohort: a nested case-control study of the Drakenstein child health study. Lancet Respir Med. 2016;4(6):463-72.

29. Awasthi S, Rastogi T, Mishra N, Chauhan A, Mohindra N, Shukla RC, et al. Chest radiograph findings in children aged 2-59 months hospitalised with community-acquired pneumonia, prior to the introduction of pneumococcal conjugate vaccine in India: a prospective multisite observational study. BMJ Open. 2020;10(5):e034066.

30. Menendez R, Torres A. Treatment failure in community-acquired pneumonia. Chest. 2007;132(4):1348-55. https://doi.org/10.1378/chest. 06-1995.

31. Seear M, Awasthi S, Gowraiah V, Kapoor R, Awasthi A, Verma A, et al. Predictive accuracy of chest radiographs in diagnosing Tachypneic children. Indian J Pediatr. 2016;83(9):930-6. https://doi.org/10.1007/ s12098-016-2057-7.

32. Hassen M, Toma A, Tesfay M, Degafu E, Bekele S, Ayalew F, et al. Radiologic diagnosis and hospitalization among children with severe community acquired pneumonia: a prospective cohort study. Biomed Res Int. 2019:2019.

33. Nizami SQ, Bhutta ZA, Hasan R, Husen YA. Role of chest $X$-ray in diagnosis of lower respiratory tract infections in children less than five years of age in community. Pakistan J Med Sci. 2005;21(4):417-21.

34. Madhi SA, Klugman KP. World Health Organisation definition of "radiologically-confirmed pneumonia" may under-estimate the true public health value of conjugate pneumococcal vaccines. Vaccine. 2007;25(13):2413-9.

35. Yan C, Hui R, Lijuan Z, Zhou Y. Lung ultrasound vs. chest X-ray in children with suspected pneumonia confirmed by chest computed tomography: a retrospective cohort study. Exp Ther Med. 2019:1363-9.

36. Heuvelings CC, Bélard S, Familusi MA, Spijker R, Grobusch MP, Zar HJ. Chest ultrasound for the diagnosis of paediatric pulmonary diseases: a systematic review and meta-analysis of diagnostic test accuracy. Br Med Bull. 2019;129(1):69-78.

37. Wang W, Zhu Y, Yin L, Deng Y, Chu G, Liu S. Utilization of serum procalcitonin as a biomarker in the diagnosis and treatment of children with bacterial hospital-acquired pneumonia. Mol Cell Biochem. 2020:1-7. https://doi.org/10.1007/s11010-020-03902-8.

38. Florin TA, Ambroggio L, Brokamp C, Brokamp C, Zhang Y, Zhang Y, et al. Biomarkers and disease severity in children with community-acquired pneumonia. Pediatrics. 2020;145(6):e20193728.

39. World Health Organization. Hospital care for children pocket book. 2013.

40. Morgan H, Pettet G, Reed M, Paul SP. Indications for chest X-rays in children and how to obtain and interpret them. Nurs Child Young People. 2018;30(6):30-7.

41. Heuvelings CC, Bélard S, Andronikou S, Lederman H, Moodley H, Grobusch MP, et al. Chest ultrasound compared to chest $X$-ray for pediatric pulmonary tuberculosis. Pediatr Pulmonol. 2019;54(12):1914-20.

42. Iorio G, Capasso M, Prisco S, De Luca G, Mancusi C, Laganà B, et al. Lung ultrasound findings undetectable by chest radiography in children with community-acquired pneumonia. Ultrasound Med Biol. 2018:44(8):1687-93.

43. Ginsburg AS, Lenahan JL, Jehan F, Bila R, Lamorte A, Hwang J, et al. Performance of lung ultrasound in the diagnosis of pediatric pneumonia in Mozambique and Pakistan. Pediatr Pulmonol. 2021;56(2):551-60.

44. Buonsenso D, De Rose C. Implementation of lung ultrasound in low- to middle-income countries: a new challenge global health? Eur J Pediatr. 2021:1-8. https://doi.org/10.1007/s00431-021-04179-9.

45. Berce V, Tomazin M, Gorenjak M, Berce T, Lovrenčič B. The usefulness of lung ultrasound for the Aetiological diagnosis of community-acquired pneumonia in children. Sci Rep. 2019;9(1):1-10.
46. Ginsburg AS, Nisar I, Madrid L, Lenahan JL, Balouch B, Vitorino P, et al. Serial lung ultrasounds in pediatric pneumonia in Mozambique and Pakistan. Sci Rep. 2021;11(1):1-7.

47. Leopold SJ, Ghose A, Plewes KA, Mazumder S, Pisani L, Kingston HWF, et al. Point-of-care lung ultrasound for the detection of pulmonary manifestations of malaria and sepsis: an observational study. PLoS One. 2018;13(12):1-14

48. Hajalioghli P, Nemati M, Saleh LD, Fouladi DF. Can chest computed tomography be replaced by lung ultrasonography with or without plain chest radiography in pediatric pneumonia? J Thorac Imaging. 2016;31(4):247-52.

49. Basnet S, Sharma A, Mathisen M, Shrestha PS, Ghimire RK, Shrestha DM, et al. Predictors of duration and treatment failure of severe pneumonia in hospitalized young nepalese children. PLoS One. 2015;10(3):1-12. https:/ doi.org/10.1371/journal.pone.0122052.

\section{Publisher's Note}

Springer Nature remains neutral with regard to jurisdictional claims in published maps and institutional affiliations.

Ready to submit your research? Choose BMC and benefit from:

- fast, convenient online submission

- thorough peer review by experienced researchers in your field

- rapid publication on acceptance

- support for research data, including large and complex data types

- gold Open Access which fosters wider collaboration and increased citations

- maximum visibility for your research: over $100 \mathrm{M}$ website views per year

At BMC, research is always in progress.

Learn more biomedcentral.com/submissions 